Research Article

\title{
Development and Characterization of In Situ Gel Containing Leflunomide as a Gastro-retentive Drug Delivery
}

\author{
${ }^{1}$ Asmaa H. Esmaeil ${ }^{*}{ }^{1,2}$ Afaf A. Ramadan, ${ }^{1,3}$ Asmaa M. Elbakry \\ ${ }^{1}$ Department of Pharmaceutics and Industrial Pharmacy, Faculty of Pharmacy, Al-Azhar University (Girls), Cairo, Egypt. \\ ${ }^{2}$ Department of Pharmaceutics and Pharmaceutical Technology, Faculty of Pharmacy, Egyptian Russian University, Badr City, Egypt. \\ ${ }^{3}$ Department of Pharmaceutics and Pharmaceutical Technology, Faculty of Pharmacy, Heliopolis University, Cairo, Egypt. \\ *Corresponding author's E-mail: asmaaesmaeil@ymail.com
}

Received: 18-07-2020; Revised: 20-09-2020; Accepted: 26-09-2020; Published on: 20-10-2020.

\begin{abstract}
The objective of the present study was to develop and evaluate an oral floating in situ gel of leflunomide (LEF) as liquid gastroretentive drug delivery system for treatment of Juvenile Rheumatoid Arthritis (JRA) to improve patient compliance, prolong its gastric residence time, and reduce the variations of drug concentration in plasma. LEF is a disease modifying anti-rheumatic drug (DMARD) which effectively reduces the signs and symptoms of active JRA in children and rheumatoid arthritis (RA) in adults. Floating in situ gelling formulations were prepared using different concentrations of sodium alginate and calcium carbonate. The prepared gels were characterized for viscosity, drug content, $\mathrm{pH}$, density, in-vitro gelling capacity, floating lag time, floating duration, gelling strength and in-vitro release study. The formula $\mathrm{C} 4$ (containing $1.5 \% \mathrm{w} / \mathrm{v}$ sodium alginate and $1 \% \mathrm{w} / \mathrm{v}$ calcium carbonate) was considered the best formula since it showed minimum floating lag time ( $40 \mathrm{sec}$ ), optimum viscosity ( $295.4 \mathrm{cps}$ ), and gel strength ( $45 \mathrm{sec}$ ) and has optimum drug release (98\%) for more than $6 \mathrm{hr}$. Therefore, this formula was chosen for further ex-vivo study in rats to detect gel formation in the stomach. Formula C4 showed good gel formation ex vivo study. Hence, floating in situ gelling system of LEF is considered a novel approach to increase patient compliance and increase gastric residence time of drug in the stomach, which in turn will maintain its plasma level.
\end{abstract}

Keywords: Leflunomide, Juvenile Rheumatoid Arthritis, Floating in Situ Gel, Gastric Residence Time, Gastro-retentive drug delivery.

QUICK RESPONSE CODE $\rightarrow$

DOI:

10.47583/ijpsrr.2020.v64i02.002

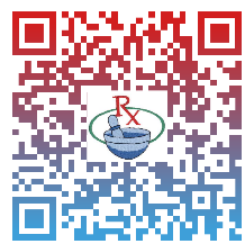

DOI link: http://dx.doi.org/10.47583/ijpsrr.2020.v64i02.002

\section{INTRODUCTION}

T he oral administration route is preferred over the various other administration routes of drug delivery due to the many advantages it exhibits. These advantages include safety, good patient compliance, ease of ingestion, pain avoidance, and versatility to accommodate various types of drugs ${ }^{1}$.

Solid dosage forms may associate with swallowing problems for geriatric, pediatrics and bedridden patient and chances of accidental burst release. To solve the above-mentioned problems, pharmaceutical technologists have put in their best efforts to develop a Gastro-retentive liquid dosage forms i.e. in situ gel formulations. The oral use of liquid pharmaceutical has generally been justified on the basis of ease of administration to those individuals who have difficulty swallowing solid dosage forms and better patient compliance ${ }^{2}$.

The in-situ gel dosage form is a liquid before administration but converts into a gel that floats on gastric contents as it comes in contact with it. It consists of a solution of low viscosity that on coming in contact with the gastric fluids, undergoes change in polymeric conformation, viscous gel having density lower than the gastric fluids thus floats on the surface of $\mathrm{it}^{3}$.

Gastro-retentive in situ gel forming system provides the controlled drug delivery within stomach. In situ gel formation occurs due to one or combination of different stimuli like $\mathrm{pH}$ change, temperature modulation and solvent exchange ${ }^{4}$

Formulation of gastro-retentive sol-gel system involves the use of gelling agent which can form a stable sol system to contain the dispersed drug and other excipients. The gelling of this sol system is to be achieved in gastric environment, triggered by ionic complexation due to the change in $\mathrm{pH}$. The formulation adopted is a sodium alginate solution containing calcium carbonate (as a source of $\mathrm{Ca}^{2+}$ ) and sodium citrate, which complexes the free $\mathrm{Ca}^{2+}$ ions and releases them only in the acidic environment of the stomach. The free $\mathrm{Ca}^{2+}$ ions get entrapped in polymeric chains of sodium alginate thereby causing cross-linking of polymer chains to form matrix structure. This gelation involves the formation of double helical junction zones followed by re-aggregation of the double helical segments to form a three-dimensional network by complexation with cations and hydrogen bonding with water ${ }^{5}$.

Juvenile idiopathic arthritis (JIA) is a chronic autoimmuneinflammatory disease of unknown etiology. JIA affects up 
to 1 to 4 per 1,000 children worldwide and is the most common cause of autoimmune musculoskeletal disease in children. Children with JIA have disease onset prior to age 16 years, and present with joint pain, stiffness and swelling that persists for longer than 6 weeks $^{6}$.

Leflunomide is an isoxazole derivative, a disease modifying anti-rheumatic drug (DMARD) which effectively reduces the signs and symptoms of JRA in children, while inhibiting joint damage and improving physical function. The mechanism of action of this drug is mainly owing to the inhibition of dihydro-orotate dehydrogenase and tyrosine kinase enzymes ${ }^{7}$.

LEF is a pro-drug and after oral administration, rapidly metabolized to its major active form (Teriflunomide) in the gut wall, plasma and in the liver. It is practically insoluble in water and is absorbed from gastrointestinal tract at high rate following the oral administration but undergoes extensive first pass metabolism. Oral bioavailability of LEF is $80 \%$ for humans ${ }^{8}$. In order to maintain therapeutic plasma levels, sustained release (SR) dosage forms may be beneficial, allowing only one daily administration of the drug with consequent improvement of patient compliance. Sustained release drug delivery aimed at controlling the release rate as well as maintains desired drug level in the blood which is therapeutically effective and non-toxic for extended period of time.

\section{MATERIALS AND METHODS}

Leflunomide pure sample was kindly supplied by Al Hekma pharm (Egypt). Sodium alginate was kindly supplied by Al Kahira Co. (Egypt). Hydrochloric acid, Calcium carbonate and Sodium citrate were purchased from El-Nasr pharmaceutical Co. (Egypt).

\section{Drug -polymer compatibility studies}

\section{Fourier transform infrared spectroscopy (FTIR)}

FTIR Spectra of LEF, sodium alginate and LEF-sodium alginate physical mixture $(1: 1 \mathrm{w} / \mathrm{w})$ were recorded with an FTIR spectrometer (Shimadzu, Model-8400 S, Japan) using potassium bromide disc method. All spectra were recorded from $400-4000 \mathrm{~cm}-1$ with an empty pellet holder as reference ${ }^{9}$.

\section{Differential scanning calorimetry (DSC)}

The thermal properties of LEF, sodium alginate and LEFsodium alginate physical mixture $(1: 1 \mathrm{w} / \mathrm{w})$ were investigated using DSC (Shimadzu, Model DSC-50, Japan). Samples were weighed and encapsulated into flat bottomed aluminum pans with crimped-on lids. The scanning speed of $10^{\circ} \mathrm{C} / \mathrm{min}$ from $25^{\circ} \mathrm{C}$ to $400^{\circ} \mathrm{C}$ was used in presence of nitrogen at flow rate of $25 \mathrm{ml} / \mathrm{min}$. A thermogram is obtained over the temperature range used with a thermal analyzer equipped with computer soft program. The instrument was calibrated with pure indium as reference. Compatibility of materials was identified by observing any changes occurred in melting points of the drug $^{10}$.

\section{Preparation of in situ gel}

Floating in situ gel formulations of LEF were prepared using different concentrations of gelling polymer (sodium alginate) and complexing agent $\left(\mathrm{CaCO}_{3}\right)$. In $70 \mathrm{ml}$ of deionized water, various quantities of sodium alginate and $0.25 \% \mathrm{w} / \mathrm{v}$ sodium citrate was dissolved at $60^{\circ} \mathrm{C}$ using a heating magnetic stirrer. After cooling to below $40^{\circ} \mathrm{C}$, the weighed amount the drug (400mg), along with various quantities of calcium carbonate were dispersed uniformly into the sodium alginate solution with continuous stirring. The stirring was continued after complete addition until a uniform dispersion was obtained and the dispersion was allowed to cool at room temperature. Finally, the volume was adjusted to $100 \mathrm{ml}$ with deionized and the mixture was mixed well to get the final preparation which was stored in amber color bottles until further use $\mathrm{e}^{11}$.

\section{Selection of working concentration range of gelling polymer}

Various formulations were prepared using sodium alginate as gelling polymer to select working concentration range of gelling polymers on basis of in vitro gelling capacity, $\mathrm{pH}$ and pourability (relative viscosity). The rest of ingredients were not changed ${ }^{12}$.

Batches "S" were prepared to study the effect of sodium alginate concentration on physical properties of the in situ gel as pourability, gel strength, $\mathrm{pH}$, density, swelling index and gelling capacity. The concentration of sodium alginate was varied from $0.5,1,1.5,2$ and $2.5 \%$ in batches S1 to S5, respectively as shown in table (1).

\section{Selection of working concentration range of complexing agent}

Various formulations were prepared using calcium carbonate as complexing agent to select working concentration range of complexing agent on basis of its effect on physical properties, floating properties and release pattern ${ }^{12}$.

Batches "C" were prepared to study the effect of calcium carbonate concentration on in-vitro release, the floating lag time, gel strength, $\mathrm{pH}$, viscosity and the other physical properties of the in-situ gel. The concentration of calcium carbonate was varied from $0.25,0.5,0.75,1.0$ and $1.5 \%$ in batches of $\mathrm{C} 1$ to $\mathrm{C} 5$, respectively as shown in table (3). Weight of sodium citrate $(0.25 \% \mathrm{w} / \mathrm{v})$ was kept constant in all batches of "S" and " $\mathrm{C}$ ".

\section{Characterization of LEF in situ gel formulations for selection of working concentration range of gelling polymer and complexing agent}

All prepared LEF in situ gel formulations were evaluated to determine physical appearance, $\mathrm{pH}$, drug content, density, in-vitro gelation and floating studies, viscosity and gel strength, Also, in-vitro release and kinetic analysis of release data of LEF from different in situ gel formulations was determined. 


\section{Determination of the physical appearance}

All the formulations were visually inspected for their appearance and pourability.

\section{Measurement of the $\mathrm{pH}$}

The $\mathrm{pH}$ for each of the formulations was measured using a calibrated $\mathrm{pH}$ meter (410A, ORION). The readings were recorded in triplicate for each formulation and the averages of the readings were considered ${ }^{13}$.

\section{Determination of drug content uniformity}

Accurately, five milliliters of in situ gel (equivalent to $20 \mathrm{mg}$ of LEF) was measured and transferred to $1000 \mathrm{ml}$ volumetric flask. To this $900 \mathrm{ml}$ of $0.1 \mathrm{~N} \mathrm{HCl}$ was added and stirred on magnetic stirrer (Thennolyne, Dubuque, U.S.A.) for $30 \mathrm{hr}$, followed by sonication (UP 400S, Germany) for 15 min. Complete dispersion of contents was ensured visually and filtered. From this solution, $1 \mathrm{ml}$ of sample was withdrawn and diluted to $10 \mathrm{ml}$ with $0.1 \mathrm{~N} \mathrm{HCl}$. Contents of LEF were determined spectrophotometrically at $\lambda_{\max } 260$ nm using UV spectrophotometer (Shimadzu, UV-1601, Japan). The measurements of drug content were recorded in triplicate and the average values are calculated ${ }^{14}$.

\section{Determination of Density}

Density of the floating oral in situ gel was determined by using water displacement method. To $(10 \mathrm{ml})$ in situ solution, $20 \mathrm{ml}$ of $0.1 \mathrm{~N} \mathrm{HCl}(\mathrm{pH} \mathrm{1.2)}$ was added to convert the solution into gel. Excess of $\mathrm{HCl}$ was drained off and the gel formed was weighed. The gel was then transferred to a $50 \mathrm{ml}$ measuring cylinder and allowed to settle at the base. Distilled water was added up to $50 \mathrm{ml}$ marking of measuring cylinder. Volume of water in the presence of gel was noted. From the difference in the volumes of water with and without gel the volume of gel was obtained i.e. amount of water displaced by the gel was calculated ${ }^{15}$.

\section{In vitro gelation study}

Five milliliters of the simulated gastric fluid $(0.1 \mathrm{~N} \mathrm{HCl}, \mathrm{pH}$ 1.2 ) in a $15 \mathrm{ml}$ test tube maintained at $37^{\circ} \mathrm{C}$ followed by the addition of $1 \mathrm{ml}$ of the formulation using a pipette. The pipette was positioned facing the surface of the fluid in the test tube and slowly the formulation was released from the pipette. When the formulation came in contact with the gelation medium, it was quickly converted into a gel-like structure. Based on the stiffness of gel as well as the duration, for which the gel remains as such, the in-vitro gelling capacity was investigated ${ }^{16}$.

The in vitro gelling capacity was mainly divided into three categories based on immediate gelation time and extended period, the formed gel remains.

(+) Gels within five min, dispersed within $4 \mathrm{hr}$

$(++)$ Gels within $60 \mathrm{sec}$ and retains gel structure for up to $8 \mathrm{hr}$.

$(+++)$ Gels immediately and retains gel structure for up to $12 \mathrm{hr}$.

\section{In vitro floating study}

The in vitro floating study was carried out by introducing $10 \mathrm{~mL}$ of formulation into a beaker containing $100 \mathrm{ml}$ of $0.1 \mathrm{~N} \mathrm{HCl},(\mathrm{pH} 1.2)$ at $37^{\circ} \mathrm{C}$ without much disturbance.

The time required for the formulation to emerge on the medium surface (floating lag time) and the time the formulation constantly floated on surface of the dissolution medium (duration of floating) were recorded $1^{7,18}$.

\section{Measurement of viscosity}

Viscosity of the prepared in situ gel was determined by Brookfield viscometer (Model DV-II, Germany). The samples $(10 \mathrm{ml})$ were sheared at a rate of $50 \mathrm{rpm} / \mathrm{min}$ using spindle number 2 at room temperature. Viscosity measurement of each sample was done in triplicate, each measurement taking approximately $30 \mathrm{sec}^{19}$.

\section{Measurement of gel strength}

A sample of $50 \mathrm{~g}$ of the gel formed in $0.1 \mathrm{~N} \mathrm{HCl}(\mathrm{pH} \mathrm{1.2)} \mathrm{was}$ introduced into a $100 \mathrm{ml}$ graduated cylinder. A weight of $35 \mathrm{~g}$ was placed onto the center of the surface of the gel and allowed to penetrate through the gel. The time taken by the $35 \mathrm{~g}$ weight to penetrate $5 \mathrm{~cm}$ down through the gel was noted for all formulations. The same procedures were followed for each fresh formulation in triplicate and average time was determined ${ }^{20}$.

\section{In vitro release studies}

The drug release studies were carried out in USP type II dissolution test apparatus (DA6D, Bombay, India) at $37 \pm$ $0.5^{\circ} \mathrm{C}$ and at $50 \mathrm{rpm}$. This speed was slow enough to avoid the breaking of gelled formulation and maintained the mild agitation conditions believed to exist in vivo. Dissolution medium was $900 \mathrm{ml}$ of $0.1 \mathrm{~N} \mathrm{HCl}$ buffer solution $(\mathrm{pH} 1.2)$. A specified amount of in situ gel $(5 \mathrm{ml})$ equivalent to $20 \mathrm{mg}$ of LEF was used for test. $5 \mathrm{ml}$ of aliquots were withdrawn at predetermined time intervals. The withdrawn samples were replaced immediately with an equal volume of fresh buffer. The samples were filtered and assayed spectrophotometrically at $\lambda_{\max } 260 \mathrm{~nm}$. The measurements were carried out in triplicates and the results were presented as percentage of cumulative LEF released against each corresponding time ${ }^{21}$.

\section{Kinetics analysis of drug release data}

The dissolution profile of all the batches were fitted to zero-order, first-order, second-o ${ }^{8}$ rder and Higuchi kinetics to ascertain the kinetic modeling of drug release by using a PCP Disso Version 2.08 software, and the model with the higher correlation coefficient was considered to be the best fit model ${ }^{22}$.

\section{Ex-vivo Gelation study}

The best formula was subjected to ex-vivo gelation study to check in situ gel formation in stomach. Six male albino rats weighing 200-220 g was randomly divided into two groups (three animals per group). Group -1 : served as 
control and Group -2: served as treated. The animals were fasted for $24 \mathrm{~h}$ prior to the experiment but allowed free access to water. The amount of drug for tested group was equivalent to $2 \mathrm{mg} / \mathrm{kg}$. Control animals in group -1 were administered normal saline orally and then, sacrificed and stomach was removed, cut along with the greater curvature. While rats in group-2 were administered selected in situ gel formulation orally and after $3 \mathrm{~h}$ animals were sacrificed. Stomach was removed outside and cut along with the greater curvature to observe weather gel forms or not ${ }^{23}$.

\section{RESULTS AND DISCUSSION}

\section{Drug - polymer compatibility studies}

\section{Fourier Transform Infrared spectroscopy (FTIR)}

The compatibility of LEF with the excipients was confirmed by FTIR spectroscopy. The FTIR spectrum of LEF alone is illustrated in figure (1-a) which characterized by clear sharp characteristic peak at $3356 \mathrm{~cm}^{-1}$. This peak is attributed to $\mathrm{N}-\mathrm{H}$ stretching band of secondary amine group and a sharp peak appearing at $3066 \mathrm{~cm}^{-1}$ in spectrum which is assigned to $\mathrm{C}-\mathrm{H}$ stretching vibration of benzene ring. At low frequencies, a sharp peak appears at $1693 \mathrm{~cm}^{-}$ ${ }^{1}$ is attributed to $\mathrm{HC}=\mathrm{N}-\mathrm{O}$ group in isoxazole ring. Also, a sharp peak at $1604 \mathrm{~cm}^{-1}$ is assigned to $\mathrm{C}=\mathrm{O}$ of amide and a peak at $1539 \mathrm{~cm}^{-1}$ is attributed to $\mathrm{C}=\mathrm{C}^{9,10}$.

An IR spectrum of sodium alginate alone is shown in figure (1-b) exhibited major band at $3417 \mathrm{~cm}^{-1}$ at high frequency for $\mathrm{OH}$ group. The band at $2935 \mathrm{~cm}^{-1}$ was due to $-\mathrm{CH}_{2}$ group. In addition, bands at 1415 and $1604 \mathrm{~cm}^{-1}$ which are characteristic to asymmetric and symmetric stretching bands of carboxylate salt group -COO. The band at 1033 $\mathrm{cm}^{-1}$ was due to $\mathrm{C}-\mathrm{O}-\mathrm{C}$ stretching vibration ${ }^{24}$. FTIR spectrum of physical mixture of LEF and sodium alginate $(1: 1 w / w)$ is shown in figure (1-c). It was observed that principle peaks of drug were found to be in FTIR spectrum of physical mixture of drug and polymer at the same positions. It was suggested that there was no physical or chemical interaction between drug and polymer.

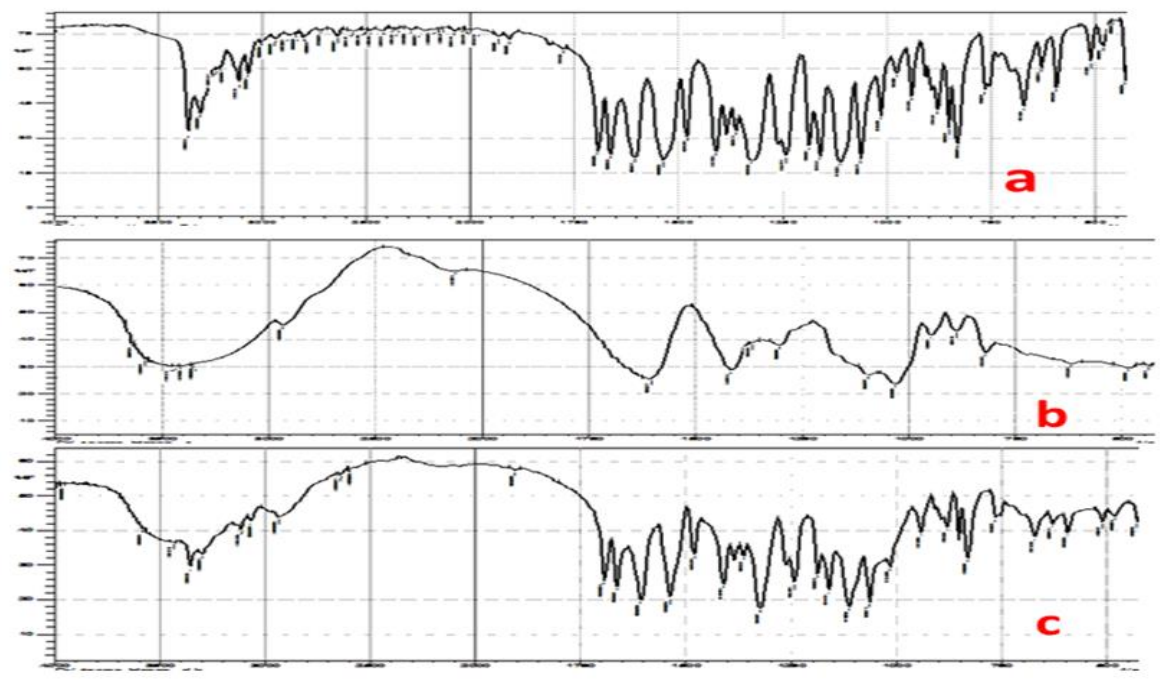

Figure 1: FTIR spectra of (a) LEF, (b) sodium alginate, (c) LEF- sodium alginate physical mixture (1:1 w/w)

\section{Differential Scanning Calorimetry (DSC)}

Interactions in the samples are derived from DSC by changes in the thermal events, such as elimination of an endotherm or exotherm peak, or appearance of a new peak.

Figure (2-a) shows the DSC thermogram of LEF alone which is characterized by sharp endothermic peak at $166.06^{\circ} \mathrm{C}$ corresponds the melting point of drug indicating its crystalline nature. This is in good agreement with the previous finding on thermal analysis of LEF by Krishnan et al., $2018^{25}$.

Figure (2-b) shows the DSC thermogram of sodium alginate alone which is characterized by endothermic peak at $119.16^{\circ} \mathrm{C}$ due to removal of absorbed moisture, finally a sharp exothermic peak at $235.84^{\circ} \mathrm{C}$ due to alginate decomposition ${ }^{26}$.
The DSC thermogram of physical mixture of LEF and sodium alginate $(1: 1 \mathrm{w} / \mathrm{w})$ is shown in figure $(2-c)$. The thermogram shows the characteristic endothermic peak of the drug with little shift at 164.67 oc indicating compatibility between drug and polymer.

Characterization of LEF in situ gel formulations for selection of working concentration range of gelling polymer and complexing agent

\section{Selection of working concentration range of gelling polymer}

All the prepared formulations had off-white appearance and showed no lumps in the preparation as shown in figure (3). The formulations did not produce any gelation at room temperature. 


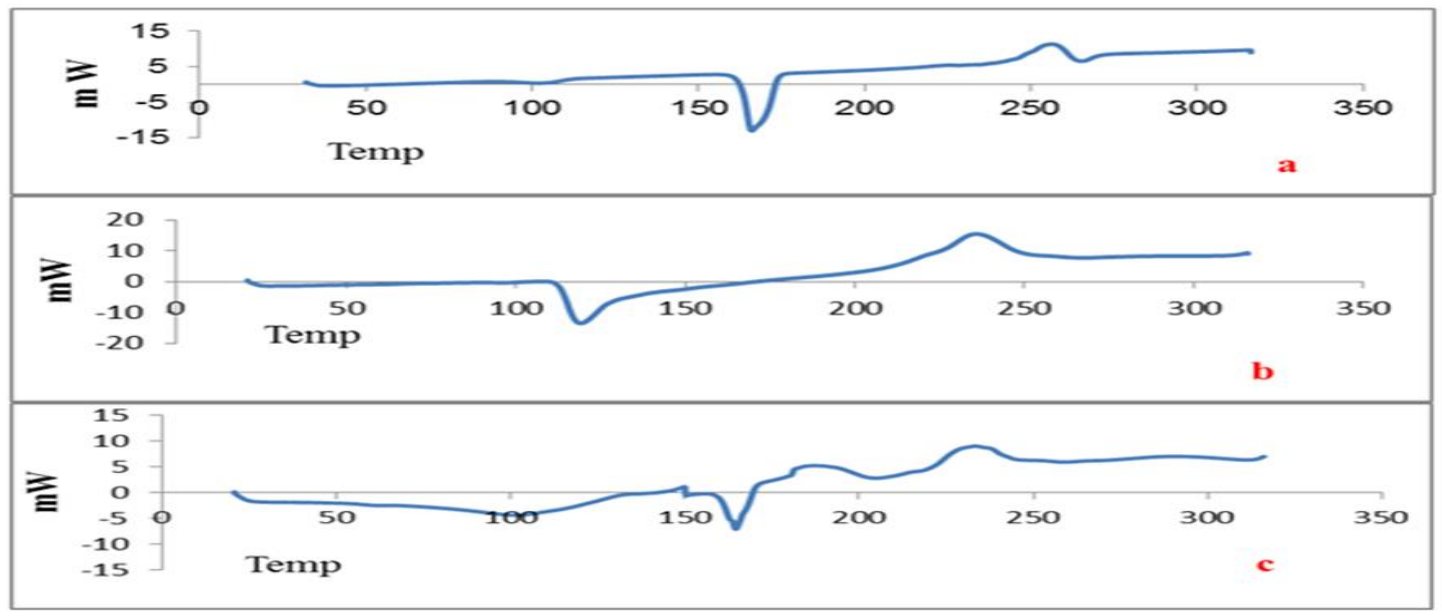

Figure 2: DSC thermograms of (a) LEF, (b) sodium alginate, (c) LEF-sodium alginate physical mixture (1:1 w/w)
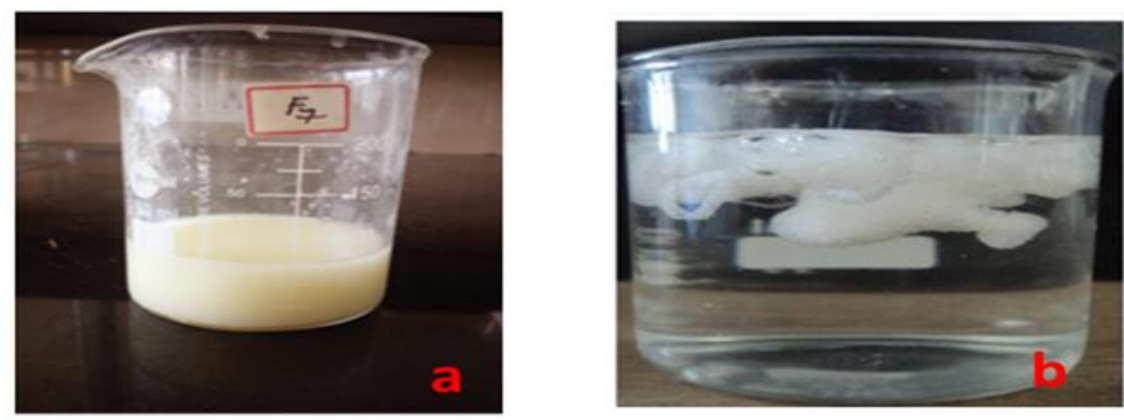

Figure 3: In situ gel formulation of LE, (a) in situ gel solution at room temperature, $\quad$ (b) floating in situ gel at $\mathrm{pH} 1.2$

As shown in table (1), Batches S1 to S5 were prepared to study the effect of sodium alginate concentration on the floating lag time and gel strength, $\mathrm{pH}$, density and the other physical properties of the gel in $\mathrm{pH}$ 1.2.

The $\mathrm{pH}$ values were determined for each in situ gel formulations and the results were revealed in table (1). The formulations possessed satisfactory $\mathrm{pH}$ value ranging from 8.62 to 9.2 which is suitable to maintain the formulations in a liquid state. Aqueous solutions of sodium alginate are most stable at $\mathrm{pH}$ range of $4-10$. Below $\mathrm{pH} 3$, alginic acid is precipitated from the alginate solution making the formulation unsightly containing gel and liquid phases ${ }^{5}$.

All formulations have density lower than gastric content, which is $\sim 1.004 \mathrm{~g} / \mathrm{cm}^{3}$, thus ensuring their buoyancy. As shown in table (1), the densities of formulations were ranged between $0.350-0.73 \mathrm{~g} / \mathrm{cm}^{3}{ }^{11}$.

All the formulations showed good gel strength which ranged from $17-42 \mathrm{sec}$. Gel strength demonstrates the ability of the gelled mass to withstand the peristaltic movement in "in-vivo".

The solutions showed a marked increase in viscosity with increasing concentration of sodium alginate $(0.5-2.5 \%$ $\mathrm{w} / \mathrm{v})$. This is attributed to a consequence of increasing chain interaction with an increase in polymer concentration ${ }^{19}$.
S1 and S2 formulations which contain low concentration of sodium alginate showed improper gelation when contacted with $0.1 \mathrm{~N} \mathrm{HCL}(\mathrm{pH}$ 1.2) which leads to a rapid flow of the formulation and also the time required for gelation was also very long. Formulations which contain higher concentrations of sodium alginate showed instantaneous gelation when contacted with $0.1 \mathrm{~N} \mathrm{HCl}(\mathrm{pH}$ 1.2) but the viscosity of the solutions is high so they were difficult to be poured.

The gelling capacity for all formulations showed soft gel formation which dispersed within $4 \mathrm{hr}$, S2 batch showed immediate gelation that remains for $8 \mathrm{~h}(++)$ while S3 to S5 batches showed immediate gelation that remains for more than 12 hours $(+++)$. It is obvious that, sodium alginate at $1 \%$ concentration form stiff gel while below $1 \%$, gel is formed but ruptured, and these results are in agreement with chaniyara et al., $2013^{27}$. Among all of these batches (from S1 to S5), batch S3 has optimum viscosity (245.6 cp) and has enough gel capacity.

From figure (4), it is obvious that increasing the polymer concentration in the prepared formulations caused decrease in rate of drug release. This effect is attributed to increase of the polymer concentration, more polymeric chains are available for crosslinking with the calcium ion. As the crosslinking increases, it forms a stronger gel, across which drug diffusion becomes difficult ${ }^{28}$. Table (2) shows the kinetic analysis of the in-vitro dissolution data of LEF 
from different in situ gels. According to correlation coefficient ( $r$ ), it was found that the in-vitro release of LEF from different in situ gels followed zero- order model.

On bases of these evaluation parameters, S3 was selected as promising formula. So, working concentration of sodium alginate that was selected is $1.5 \% \mathrm{w} / \mathrm{v}$ for further studies.

\section{Selection of working concentration range of complexing agent}

The $\mathrm{pH}$ values were determined for each in situ gel formulations and the results are shown in table (3). The formulations possessed satisfactory $\mathrm{pH}$ value ranging from 9.01 to 9.3 which is suitable to maintain the formulations in a liquid state.

All formulations have density lower than gastric content which is $\sim 1.004 \mathrm{~g} / \mathrm{cm}^{3}$, thus ensuring their buoyancy ${ }^{11}$. As shown in table (3), the densities of formulations were found to be ranged between $0.417-0.730 \mathrm{~g} / \mathrm{cm} 3$. All the formulations showed good gel strength which ranged from $20-46 \mathrm{sec}$.

As revealed in table (3), five batches (C1 to C5) were prepared with increasing concentration of calcium carbonate from $0.25-1.5 \% \mathrm{w} / \mathrm{v}$.
Batches C1 and C2, gel was formed but it ruptured and exhibit fragmentation in 3-4 h due to poor crosslinking of calcium ion because of low concentration of calcium carbonate.

Increasing calcium carbonate content in the formulation increased the viscosity of the formulations. Since the calcium carbonate is present in the formulations as insoluble dispersion, an increase in its concentration proportionally increased the number of particles dispersed, thus contributing to increased viscosity ${ }^{17}$.

C1and C2 formulations which contain low concentration of calcium carbonate showed the lowest floating behavior. In C5 batch, viscosity of the solutions was very high (446.5 cp) because of the higher concentration of calcium carbonate which leads to difficulty in pouring the solution.

From figure (5), it was observed that the drug release decreased as concentration of calcium carbonate in formulation increased. This may be attributed to the fact that as the concentration of calcium ions increases, crosslinking also increases. Only batches $\mathrm{C} 4$ and $\mathrm{C} 5$ containing $1 \%$ and $1.5 \% \mathrm{w} / \mathrm{v}$ of calcium carbonate, respectively, have cumulative percent release for more than $6 \mathrm{~h}$ suggesting better stiffness of gel.

Table 1: Composition and Evaluation of LEF in situ gels (S1-S5) for selection of working concentration ranges of gelling polymer (sodium alginate)

\begin{tabular}{|c|c|c|c|c|c|c|c|c|c|c|}
\hline \multirow{2}{*}{ 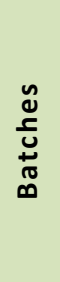 } & \multirow{2}{*}{ 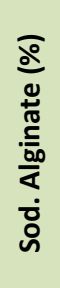 } & \multirow[b]{2}{*}{ 긍 } & \multicolumn{2}{|c|}{$\begin{array}{l}\text { Floating } \\
\text { properties }\end{array}$} & \multirow{2}{*}{ 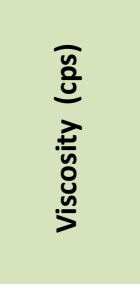 } & \multirow{2}{*}{ 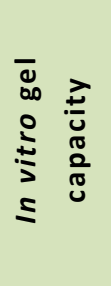 } & \multirow{2}{*}{$\begin{array}{l}\bar{m} \\
\frac{E}{u} \\
\frac{0}{00} \\
\frac{z}{n} \\
\frac{1}{n} \\
0 \\
0\end{array}$} & \multirow{2}{*}{ 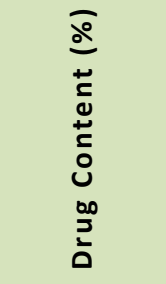 } & \multirow{2}{*}{ 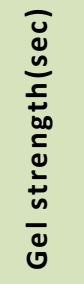 } & \multirow{2}{*}{$\begin{array}{l}\stackrel{2}{:} \\
: 0 \\
0 \\
\frac{0}{3} \\
0 \\
0\end{array}$} \\
\hline & & & 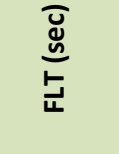 & 王 & & & & & & \\
\hline S1 & 0.5 & $8.62 \pm 0.4$ & $180 \pm 10$ & $<8$ & $155.6 \pm 21$ & + & $0.350 \pm 0.23$ & $98.5 \pm 1.13$ & $17 \pm 4$ & Easy \\
\hline S2 & 1 & $8.65 \pm 0.2$ & $95 \pm 14$ & $<12$ & $215.4 \pm 40$ & ++ & $0.417 \pm 0.17$ & $101.5 \pm 0.94$ & $23 \pm 8$ & Easy \\
\hline S3 & 1.5 & $8.66 \pm 0.5$ & $66 \pm 9$ & $>12$ & $245.6 \pm 32$ & +++ & $0.510 \pm 0.27$ & $102.3 \pm 0.53$ & $31 \pm 5$ & Pourable \\
\hline S4 & 2 & $8.91 \pm 0.3$ & $60 \pm 12$ & $>12$ & $404.7 \pm 28$ & +++ & $0.670 \pm 0.14$ & $99.5 \pm 1.32$ & $37 \pm 4$ & Difficult \\
\hline S5 & 2.5 & $9.21 \pm 0.1$ & $47 \pm 15$ & $>12$ & $498.5 \pm 36$ & +++ & $0.730 \pm 0.06$ & $97.5 \pm 1.67$ & $42 \pm 6$ & Difficult \\
\hline
\end{tabular}

* FLT: Floating lag time, FD: floating duration, all formulations contain 400mg LEF, 0.5\% CaCO3 and 0.25\% w/v sodium citrate.

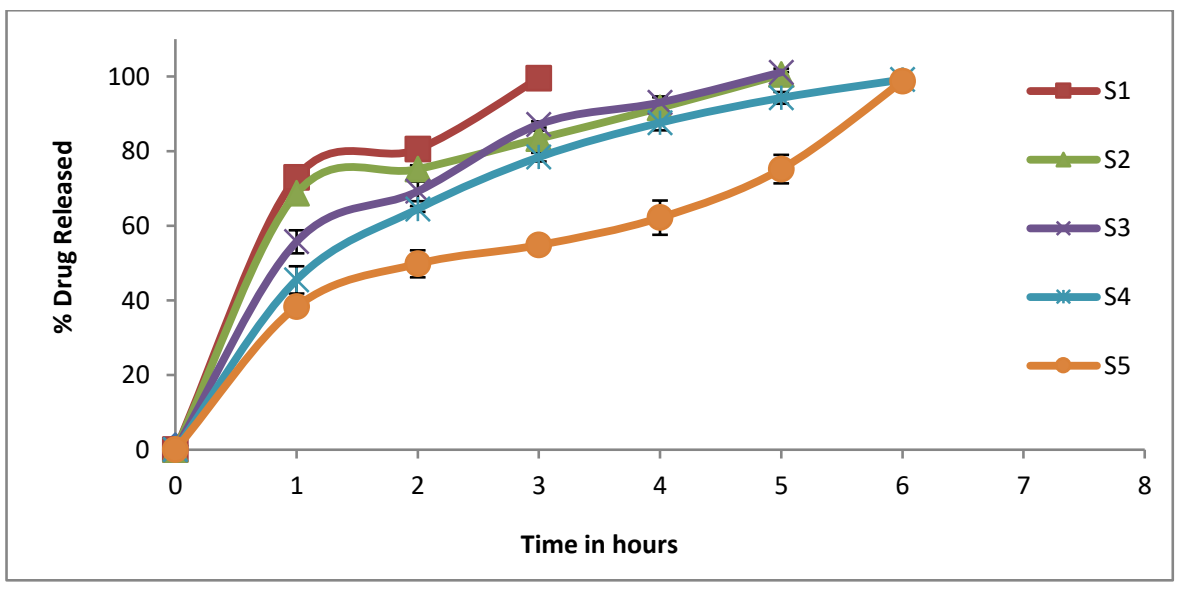

Figure 4: Effect of sodium alginate concentration on in- vitro drug release profile 
Table 2: Kinetics parameters calculated for dissolution data of LEF from in situ gel formulations (S1-S5) according to Zero, First, Second and Higuchi models

\begin{tabular}{|c|c|c|c|c|c|c|}
\hline Batch & Parameter & Zero & First & Second & Higuchi & Best model \\
\hline \multirow{5}{*}{ S1 } & $A$ & 57.733 & 2.584 & -1.484 & 35.343 & \multirow{5}{*}{ Zero } \\
\hline & B & 13.305 & -0.899 & 1.144 & 35.454 & \\
\hline & $\mathrm{R}$ & $\underline{0.970}$ & -0.899 & 0.869 & 0.949 & \\
\hline & K & 13.305 & -2.071 & 1.144 & 35.454 & \\
\hline & $t_{1 / 2}$ & 3.758 & -0.335 & 0.009 & 1.989 & \\
\hline \multirow{5}{*}{ S2 } & A & 60.052 & 2.846 & -39.954 & 41.216 & \multirow{5}{*}{ Zero } \\
\hline & B & 7.902 & -0.746 & 20.001 & 25.376 & \\
\hline & $\mathrm{R}$ & $\underline{0.999}$ & -0.801 & 0.708 & 0.987 & \\
\hline & K & 7.902 & -1.718 & 20.001 & 25.376 & \\
\hline & $t_{1 / 2}$ & 6.328 & -0.403 & 0.000 & 3.882 & \\
\hline \multirow{5}{*}{ S3 } & A & 18.956 & 2.999 & -39.964 & 47.296 & \multirow{5}{*}{ Zero } \\
\hline & B & 37.018 & -0.794 & 20.007 & 11.240 & \\
\hline & $\mathrm{R}$ & $\underline{0.991}$ & -0.839 & 0.708 & 0.977 & \\
\hline & K & 37.018 & -1.828 & 20.007 & 11.240 & \\
\hline & $t_{1 / 2}$ & 1.824 & -0.379 & 0.000 & 4.448 & \\
\hline \multirow{5}{*}{ S4 } & A & 10.861 & 2.236 & -0.382 & 41.549 & \multirow{5}{*}{ Zero } \\
\hline & B & 37.321 & -0.334 & 0.183 & 10.482 & \\
\hline & $\mathrm{R}$ & $\underline{0.993}$ & -0.950 & 0.733 & 0.990 & \\
\hline & K & 37.321 & -0.770 & 0.183 & 10.482 & \\
\hline & $t_{1 / 2}$ & 1.795 & -0.900 & 0.055 & 4.770 & \\
\hline \multirow{5}{*}{ S5 } & A & 24.613 & 2.310 & -0.234 & -3.959 & \multirow{5}{*}{ Zero } \\
\hline & B & 11.014 & -0.268 & 0.109 & 37.180 & \\
\hline & $\mathrm{R}$ & $\underline{0.966}$ & -0.795 & 0.674 & 0.937 & \\
\hline & K & 11.014 & -0.617 & 0.109 & 37.180 & \\
\hline & $\mathrm{t}_{1 / 2}$ & 4.540 & -1.123 & 0.091 & 1.809 & \\
\hline
\end{tabular}

Table (4) shows the kinetic analysis of the in-vitro dissolution data of LEF from different in situ gels. According to correlation coefficient $(r)$, it was found that the in-vitro release of LEF from different in situ gels followed zero- order model.
It is obvious that, among all of these batches (from $\mathrm{C} 1$ to C5), batch C4 has optimum viscosity, enough gel capacity and showed cumulative drug release for more than $6 \mathrm{hrs}$. On basis of these evaluation parameters and release profile, C4 was selected as promising formula. So, working concentration of calcium carbonate that was selected is $1 \%$ $\mathrm{w} / \mathrm{v}$ for further ex-vivo studies.

Table 3: formulation and Evaluation of LEF in situ gels (C1-C5) for selection of working concentration ranges of complexing agent (calcium carbonate)

\begin{tabular}{|c|c|c|c|c|c|c|c|c|c|c|}
\hline \multirow{2}{*}{ 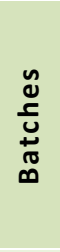 } & \multirow{2}{*}{ 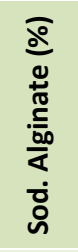 } & \multirow[b]{2}{*}{$\frac{T}{2}$} & \multicolumn{2}{|c|}{ Floating properties } & \multirow{2}{*}{ 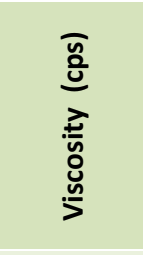 } & \multirow{2}{*}{ 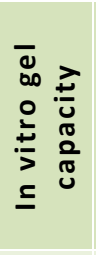 } & \multirow{2}{*}{ 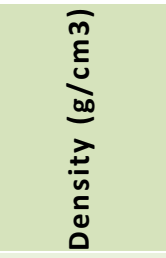 } & \multirow{2}{*}{ 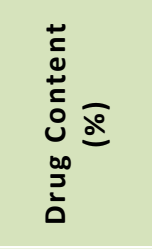 } & \multirow{2}{*}{ 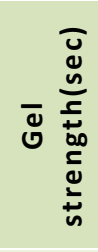 } & \multirow{2}{*}{$\begin{array}{l}\stackrel{2}{ \pm} \\
\stackrel{\overline{0}}{0} \\
\frac{\pi}{0} \\
\frac{1}{3} \\
0 \\
0\end{array}$} \\
\hline & & & 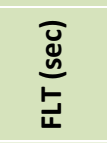 & $\frac{\text { ㄷ }}{\text { 인 }}$ & & & & & & \\
\hline C1 & 0.25 & $9.01 \pm 0.2$ & $350 \pm 6$ & $<6$ & $135.7 \pm 31$ & + & $0.417 \pm 0.18$ & $99.1 \pm 1.7$ & $20 \pm 6$ & Easy \\
\hline C2 & 0.5 & $9.25 \pm 0.1$ & $175 \pm 9$ & $<12$ & $178.4 \pm 16$ & + & $0.457 \pm 0.29$ & $101.3 \pm 1.2$ & $32 \pm 7$ & Easy \\
\hline C3 & 0.75 & $9.18 \pm 0.2$ & $86 \pm 3$ & $>12$ & $205.5 \pm 36$ & ++ & $0.525 \pm 0.14$ & $98.6 \pm 2.4$ & $35 \pm 9$ & Pourable \\
\hline C4 & 1 & $9.2 \pm 0.4$ & $40 \pm 2$ & $>12$ & $295.4 \pm 28$ & +++ & $0.570 \pm 0.21$ & $99.5 \pm 1.6$ & $45 \pm 12$ & Pourable \\
\hline C5 & 1.5 & $9.3 \pm 0.08$ & $47 \pm 5$ & $>12$ & $446.5 \pm 18$ & +++ & $0.732 \pm 0.09$ & $102.5 \pm 0.4$ & $46 \pm 15$ & Difficult \\
\hline
\end{tabular}

* FLT: Floating lag time, FD: floating duration, all formulations contain $400 \mathrm{mg}$ LEF, $1.5 \%$ sodium alginate and $0.25 \% \mathrm{w} / \mathrm{v}$ sodium citrate. 


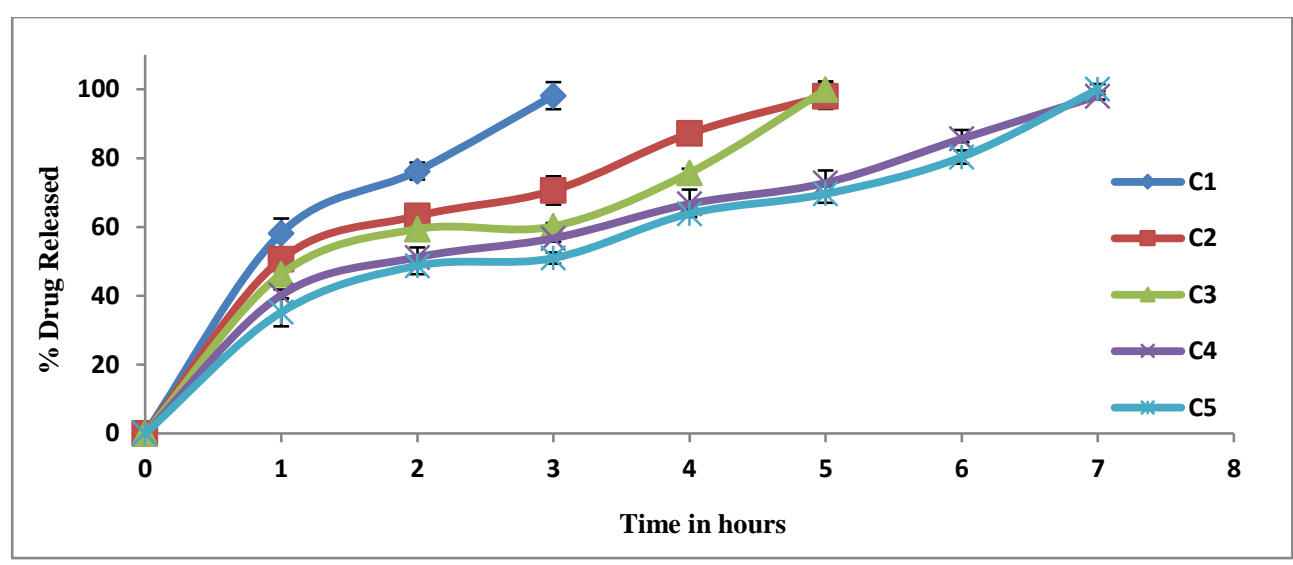

Figure 5: Effect of calcium carbonate concentration on the in-vitro drug release profile

Table 4: Kinetics parameters calculated for dissolution data of LEF from in-situ gel formulations (C1-C5) according to Zero, First, Second and Higuchi models

\begin{tabular}{|c|c|c|c|c|c|c|}
\hline Formulae & Parameter & Zero & First & Second & Higuchi & Best model \\
\hline \multirow{5}{*}{ C1 } & a & 37.587 & 2.441 & -0.312 & 2.872 & \multirow{5}{*}{ Zero } \\
\hline & B & 19.970 & -0.676 & 0.257 & 54.016 & \\
\hline & $r$ & $\underline{0.998}$ & -0.939 & 0.881 & 0.991 & \\
\hline & k & 19.970 & -1.556 & 0.257 & 54.016 & \\
\hline & $t_{1 / 2}$ & 2.504 & -0.445 & 0.039 & 0.857 & \\
\hline \multirow{5}{*}{ C2 } & $a$ & 38.267 & 2.202 & -0.173 & 9.892 & \multirow{5}{*}{ Zero } \\
\hline & $b$ & 11.881 & -0.325 & 0.102 & 38.186 & \\
\hline & $r$ & $\underline{0.995}$ & -0.912 & 0.771 & 0.984 & \\
\hline & k & 11.881 & -0.749 & 0.102 & 38.186 & \\
\hline & $\mathrm{t}_{1 / 2}$ & 4.208 & -0.926 & 0.098 & 1.714 & \\
\hline \multirow{5}{*}{ C3 } & $a$ & 31.250 & 2.770 & -3.972 & 3.097 & \multirow{5}{*}{ Zero } \\
\hline & $b$ & 12.350 & -0.568 & 1.998 & 38.893 & \\
\hline & $r$ & $\underline{0.952}$ & -0.774 & 0.708 & 0.923 & \\
\hline & $\mathrm{k}$ & 12.350 & -1.309 & 1.998 & 38.893 & \\
\hline & $t_{1 / 2}$ & 4.049 & -0.530 & 0.005 & 1.653 & \\
\hline \multirow{5}{*}{ C4 } & $a$ & 30.383 & 2.174 & -0.125 & 2.731 & \multirow{5}{*}{ Zero } \\
\hline & $b$ & 9.233 & -0.204 & 0.056 & 33.544 & \\
\hline & $r$ & $\underline{0.994}$ & -0.863 & 0.678 & 0.977 & \\
\hline & k & 9.233 & -0.469 & 0.056 & 33.544 & \\
\hline & $\mathrm{t}_{1 / 2}$ & 5.415 & -1.477 & 0.178 & 2.222 & \\
\hline \multirow{5}{*}{ C5 } & $a$ & 24.644 & 2.860 & -28.552 & -4.608 & \multirow{5}{*}{ Zero } \\
\hline & $b$ & 9.863 & -0.445 & 10.715 & 35.683 & \\
\hline & $r$ & $\underline{0.982}$ & -0.704 & 0.613 & 0.961 & \\
\hline & $\mathrm{k}$ & 9.863 & -1.026 & 10.715 & 35.683 & \\
\hline & $t_{1 / 2}$ & 5.070 & -0.675 & 0.001 & 1.963 & \\
\hline
\end{tabular}

\section{Ex-vivo Gelation study}

Results of ex-vivo gelation study showed that when the group 2 animals are sacrificed after $3 \mathrm{hr}$, the gel formed in their stomach. It was observed that formed gel remained on a mucosal layer of the stomach to release the drug in a controlled manner (Figure 6).
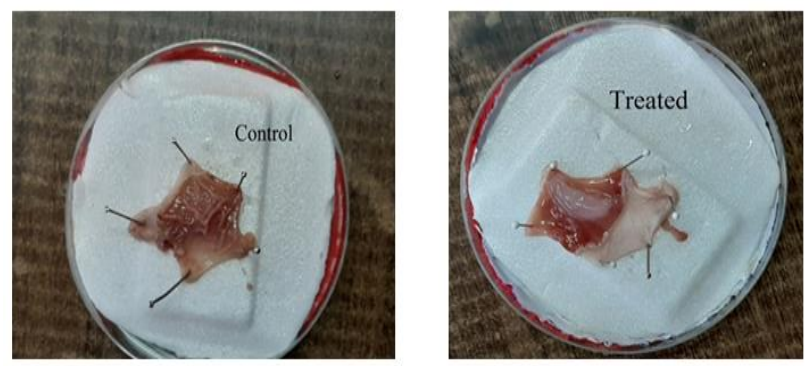

Figure 6: Ex-vivo gelation study 


\section{CONCLUSION}

In the present study in situ gel of LEF was prepared by using calcium carbonate and sodium alginate of different concentration from $(0.25-1.5 \% \mathrm{w} / \mathrm{v})$ and $(0.5-2.5 \% \mathrm{w} / \mathrm{v})$. All the prepared formulation was evaluated in order to determine the suitability for the formulation. Formula C4 (containing $1.5 \% \mathrm{w} / \mathrm{v}$ sodium alginate and $1 \% \mathrm{w} / \mathrm{v}$ calcium carbonate and $0.25 \%$ sodium citrate) was considered the best formula since it showed minimum floating lag time (40 sec), optimum viscosity (295.4 cps), and gel strength (45 sec), optimum drug release $(98 \%)$ for more than $6 \mathrm{~h}$ and good gel formation ex-vivo. On basis of preliminary studies, the best concentrations of sodium alginate and calcium carbonate selected for floating in situ gel formation are $1.5 \%$ and $1 \%$ respectively.

\section{REFERENCES}

1. Kumar MV, Formulation and Evaluation of Meclizine $\mathrm{Hcl}$ Orally Dispersible Tablets by Using Natural Super Disintegrates. Int J Pharm Sci \& Scient Res., 2(1), 2016, 53-80.

2. Wamorkar V, Varma MM and Manjunath SY, Formulation and evaluation of stomach specific in situ gel of metoclopramide using natural, bio-degradable polymers. Int J Res Pharm Biomed Sci., 2(1), 2011, 193-201.

3. Anyanwu NCJ, Adogo LY and Ajide B, Development and evaluation of in situ gelling gastro-retentive formulations of Meloxicam. Universal J Pharmaceutical Res., 2(3), 2017, 11-14.

4. Jivani RR, Patel CN, Patel DM and Jivani NP, Development of a novel floating in-situ gelling system for stomach specific drug delivery of the narrow absorption window drug Baclofen. Iranian J Pharma Res., 9(4), 2010, 359-36.

5. Temesgen A, Belete A. and Gebre-Mariam T, Preparation and In Vitro Evaluation of In Situ Gelling Gastro-retentive Salbutamol Sulfate Liquid Formulations. Int J Pharm Sci Res, 7(1), 2016, 93-101.

6. Hayward K. and Wallace C.A, Recent developments in antirheumatic drugs in pediatrics. Treatment of juvenile idiopathic arthritis. Arthritis Res \& Therapy. 11 (1), 2009, 1-11.

7. Ammar AA, Eladawy SA Elosaily GH and Amin OM, Formulation and In-Vitro Evaluation of Leflunomide Oral Tablet with Enhanced Dissolution. J American Sci., 11(12), 2015, 140-153.

8. Nagaich $U$, Deepak $P$, Sharma A, Gulati $N$ and Chaudhary $A$, Leflunomide Loaded SR Matrix Tablet: An Approach to Arthritis. RGUHS J Pharm Sci., 3(3), 2013, 20-28.

9. Padmapreetha J and Arulkumaran KSG, Effect of Kolliphor El onDissolution Rate of Leflunomide Liquisolid Compacts. J. Pharm. Sci. \& Res., 8(7), 2016, 586-593.

10. Nihal M E, Alia B, Mohammed EA and Nevine SA, Dissolution enhancement of leflunomide incorporating self-emulsifying drug delivery systems and liquisolid concepts. Bulletin Faculty of Pharmacy Cairo University, 2017, 1-10.

11. Sindhoor $S M$, Sneh $P$ and Amala $M$, Formulation and evaluation of novel in situ gel of lafutidine for gastro-retentive drug delivery. Asian J Pharmaceut and Clinical Res., 11(8), 2018, 88-94.

12. Madan J R, Adokar BR and Kamal K, Development and evaluation of in situ gel of pregabalin. Int J Pharm Investig., 5(4), 2015, 226-233.
13. Parthiban SS, Senthilkumar GP, Vikneswari A, Formulation and evaluation of gastro-retentive drug delivery of ornidazole in situ gelling system using gellan gum. Int J Res Pharm Nano Sci., 2, 2013, 747-56.

14. Bobade NN, and Shrikant DP, Formulation and Evaluation of Controlled Release Gastro-Retentive In situ Gel for Diltiazem Hydrochloride. Ind J Pharmaceut Educ and Res., 50(3), 2016, 254265.

15. Monica R P R and Swapnil U S, Controlled Release Ion Sensitive Floating Oral in situ Gel of a Prokinetic Drug using Gellan Gum. Indian Journal of Pharmaceutical Education and Research, 49 (2), 2015, 158-167.

16. Antony JE and Nair SS, Formulation and evaluation of stomach specific floating in-situ gel of clarithromycin. IJPSR. 11(3), 2020, 1479-1487.

17. Mahagen Y, Patidhar V., Balaram Y, Gopkumar P, Sridevi G, Formulation and evaluation of floatable in-situ gel for stomachspecific drug delivery of carbamazepine. Research and Reviews. J Pharm Sci., 3(1), 2014, 37-43.

18. Ramana BV, Sana SJ, Swapna CL, Sekhar SC, Ademma G and Murthy $T E$, Design and development of floating In-Situ gel of pantoprazole. Der Pharmacia Lettre, 8 (8), 2016, 239-249.

19. Dipal R P, Kanu R P and Mukesh R P, Design and development of floating in situ gel of tapentadol $\mathrm{HCl}$. Indo American J Pharmaceut Res., 6(4), 2016, 5162-5174.

20. Worrawee S, Nattha K, Thanapon P and Ruedeekorn W, Development and Evaluation of floating in situ gel for oral delivery of propranolol HCl., TJPS. 41, 2017, 65-68.

21. Khadka S, Anil KS and Junu KS, Gastro-retentive drug delivery of metoclopramide hydrochloride from a floating in situ gelling system. World journal of pharmacy and pharmaceutical sciences, 6(12), 2017, 1194-1111.

22. Darekar $A B$, Waghmare $S S$, Kadam $\mathrm{V}$ and Saudagar $\mathrm{R} B$, Development of novel floating in-situ gelling system for stomach specific drug delivery system of the narrow absorption window drug loratadine. Int J of Institutional Pharmacy and Life Sci., 6(3), 2016, 349-361.

23. Ahmed MG, Kapoor $C$ and Adinarayana $S$, Formulation and evaluation of oral sustained in situ gelling system of roxatidine. Indonesian J. Pharm., 28 (3), 2017, 179- 184.

24. Kajale $A D$ and Chandewar $A V$, Formulation and evaluation of oral floating in situ gel of Tramadol hydrochloride. The Pharmaceutical and Chemical Journal, 3(2), 2016, 267-279.

25. Krishnan Y, Mukundan S, Akhil S, Gupta S and Viswanad V, Enhanced Lymphatic Uptake of Leflunomide Loaded Nanolipid Carrier via Chylomicron Formation for the Treatment of Rheumatoid Arthritis. Adv Pharm Bull. 8(2), 2018, 257-265.

26. Chawla A, Sharma $P$, and Pawar R, Eudragit S-100 coated sodium alginate microsphere of naproxen sodium; Formulation, optimization and in-vitro evaluation. Acta Pharm., 62, 2012, 529545.

27. Chaniyara S, Modi D, Ravi P, Jay P, Rahul D, and Chaudhary S, Formulation \& Evaluation of Floatable In situ Gel for Stomachspecific Drug Delivery of Ofloxacin. American Journal of Advanced Drug Delivery, 1(3), 2013, 285-299.

28. Dawaba HM and Dawaba AM, Development and evaluation of a floating in situ gelling liquid formulation of a locally acting $\mathrm{H2}$ antagonist. Records of pharmaceutical and biomedical sciences. 2(1), 2017, 36-44.

Source of Support: None declared.

Conflict of Interest: None declared.

For any question relates to this article, please reach us at: editor@globalresearchonline.net New manuscripts for publication can be submitted at: submit@globalresearchonline.net and submit_ijpsrr@rediffmail.com 